\title{
Disability and Labour force Participation in Cameroon
}

\author{
Christian Zamo-Akono \\ Centre for Research in Applied Microeconomics (REMA) \\ Faculty of Economics and Management \\ University of Yaoundé II, Cameroon \\ E-mail: zchristy2@yahoo.fr
}

\author{
Accepted: Feb 16, 2013 Published: May 09, 2013 \\ Doi:10.5296/ijhrs.v3i2.3497 \\ URL: http://dx.doi.org/10.5296/ijhrs.v3i2.3497
}

\begin{abstract}
:
This paper examines the effect of disability on labour force participation using the Cameroon 2007 Household Survey. Statistical and econometric tests indicate that disability represents a barrier to employment in the Cameroon labour market. For instance, disability status reduces men's probability of getting into the labour market by $0.8 \%$ for the public sector, $0.05 \%$ for the formal private sector and by $2.9 \%$ for the informal sector. Other noteworthy results are the fact that women face greater constraints in entering the labour market and investments in general and specific human capital increase the probability of getting a job in the Cameroon.
\end{abstract}

Keywords: Disability, labour force participation, multinomial logit, relative risk ratios.

\section{Introduction}

Health and socio-economic status have been shown to be positively associated in human populations on every continent across the globe, in modern times and also stretching back at least several centuries. Among the broad array of indicators of health for which this association has been established, there is now overwhelming evidence that disabled people experience a substantially poorer quality of life than non-disabled peers (Daunt, 1992; Martin and White, 1988; Martin et al., 1988) and that the labour market appears as the main place where people with disabilities face many barriers to full participation in society. In fact, there are dramatic differences in labour market outcomes between disabled and non-disabled people either in terms of wages or labour force participation. As far as the latter is concerned, a number of studies consistently identify differences in employment probabilities between the two groups due to the negative employment effect of disability. Explanations of this result might be found both in disabled's labour supply behaviour and in the demand for their labour in the market.

On the supply side, a formal approach relating disability or poor health and labour market behaviour treats health as human capital (Becker, 1964; Grossman, 1972) and establishes a closed relationship between health and labour force participation. In this setting and depending on its nature, ill health might restrict the range of tasks an individual can carry out, affect the capacity to perform a job adequately as it reduces the capacity to work productively (Stronks et al 1997; Bartley and Owen 1996). Since the time needed to care for one's health increases with ill health, this reduced capacity for work coupled with difficulties in getting to and undertaking work are likely to raise he's disutility from work, increase the costs of working and thus he's 
reservation wage (Jones et al., 2003) '. Further, impairment may affect an individual's job-search process as it is likely to increase the search costs and reduce search efforts. At the end, the onset of a disability may cause individuals to value more time out of the labour market, make withdrawal from the labour market more attractive, and reduce their probability of employment, while increasing their unemployment duration.

As far as the demand side is concerned, employers may be reluctant to employ individuals with a disability, either because of concerns about their productivity or because of additional costs associated with accommodating certain types of disability. Further, the observed inferior probability of employment of the disabled may be either the result of prejudice (Becker, 1971) or due to imperfect information, where an employer uses the presence of a disability as an indicator of the productivity level of the group (Phelps, 1972), both ending to employers discriminating on the basis of disability. In this setting, the majority of disabled people, their organisations and a growing number of policy makers acknowledge that it is not impairment which prevents disabled individuals from securing an equivalent lifestyle to non-disabled people, but restrictive environments, disabling barriers and discrimination as the main cause of the problem (Barnes, 1991; Oliver, 1985; Oliver and Barnes, 1991). The existence and expectation of such discrimination may also affect the decisions of the disabled with regard to participation and investment in education resulting in the disabled having inferior characteristics in the labour market.

As many organisations and policy makers try to find the best way to tackle discrimination against disabled people on the labour market, it is important to determine whether or not working age individuals with a disability experience lower probability of employment than their non-disabled peers and understand exactly why this come about. While such an objective has received considerable empirical examination in the literature on developed countries, relatively little work has been done with developing countries data like Cameroon. This, in turn, means there is a lack of relevant empirical evidence to inform public policy regarding disability related issues for disabled persons in Cameroon. This paper fills in this gap as it disentangles differences in employment rates between disabled and non-disabled in a proportion due to lower productivity and proportion due to labour market discrimination. The remainder of this paper is structured as follows. The next section reviews the literature while section 3 provides a description of disability prevalence in Cameroun. The methodology and results are discussed in section 4 and section 5 concludes.

\section{Previous literature on disability and employment}

Many papers have modelled the probability of employment either as part of a Heckman (1976) correction for sample selection on wages or in an analysis of the effects of health conditions on the labour supply. As these studies consistently identify a negative employment effect of disability, a number of them have sought to decompose the gap in employment probabilities. Baldwin and Johnson (1992) note that the presence of wage discrimination will force some individuals to exit the labour market, and may, therefore, explain some of the observed difference in employment rates. However, Baldwin and Johnson (1994) find the disincentive effects of wage discrimination account for only two of the twenty nine percentage point difference in employment rates between disabled men subject to prejudice and non-disabled men. Similarly, in a related study for females, Baldwin and Johnson (1995) find that wage discrimination accounts for less than one percentage point of the twenty six percentage point gap in employment. Using the same methodology UK studies such as Kidd et al. (2000) also find this effect to be small in magnitude. Unlike these studies, both Blackaby et al. (1999) and 
Kidd et al. (2000) find that about half of the difference in employment probability in the UK is explained by differences in observable characteristics the remainder being due to discrimination. This view is supported by Madden (2004) who found that differences in productivity explained around $70 \%$ of the labour market participation gap between non-disabled and disabled people in UK. In India, Mitra and Sambamoorthi (2008) found that employment gap between men with disabilities and those without disabilities are not explained by observable characteristics but exclusively by discrimination.

Some studies have examined whether disability affects the type of employment undertaken and attention has been attributed to the occupational choice of disabled workers and evidence for the US (Hale et al., 1998) and the UK (Meager et al., 1998; Blackaby et al., 1999; Smith and Twomey, 2002) find disabled workers are concentrated in low skilled jobs such as administrative, secretarial, administrative skilled trades and personal services. Schumacher and Baldwin (2000) find evidence for a quality-sorting hypothesis, where, because disabled workers have a lower amount of unmeasured skill both disabled and non-disabled workers receive lower wages in occupations with a higher proportion of disabled workers. In similar research, evidence suggests that the disabled are concentrated in non-standard forms of employment, including independent contracting, part-time and temporary employment that have lower wages and fewer benefits on average (Schur, 2003). While workers with disabilities are nearly twice as likely to be self-employed as the non-disabled in the US (Blanck et al., 2000), in the UK, the rate of self-employment was also found to be higher for the disabled (Boylan and Burchardt, 2002). These high rates of self-employment were also found consistent with the higher rates of home working among the disabled (Schur and Kruse, 2002). Two central explanations were given. Firstly, employer discrimination reduces the relative wages of disabled employees, making self-employment more attractive and hence pushing disabled workers into self-employment. Secondly, the disabled may gain greater freedom and flexibility to accommodate their disability through self-employment. As she tried to determine which one of these explanations is more pertinent, Schur (2003) found that, even when personal characteristics are controlled for, flexibility required by the disabled remain the dominant reason why the disabled are significantly more likely to be in temporary and part-time employment. This evidence suggests that these forms of employment enable individuals who are unable to undertake standard types of employment to work. Consistent with this, Hotchkiss (2004) finds the disabled have a higher propensity to be employed part-time relative to the non-disabled, which is predominately due to differences in voluntary part-time employment.

\section{Disability prevalence within the working age population in Cameroon}

The empirical analysis is based on the 2007 Cameroon household survey (CHHS07). The CHHS is a survey of households conducted by the National Institute of Statistics (ONS) after five years. The survey is representative of the whole population of Cameroon and household members are interviewed on diverse aspects related to health, education, employment and incomes, migrations, households' environment, equipment and access to basic infrastructures. The 2007 CHHS covered more than 12,000 households and 50,000 individuals. To measure disability in the 2007 CHHS, individuals were asked if they suffer from a disability and for those saying yes, they were asked to choose the medical condition they have among seven categories and these have been grouped into five categories as listed in table 1. Table 1 shows that, in 2007, 4.63 per cent of the working age population in the Cameroon 2007 household survey (HHS) declared to suffer from a disability. 
Table 1: Measurement of disability and prevalence in Cameroon

\begin{tabular}{|c|c|c|c|c|c|c|c|}
\hline & $\begin{array}{c}\text { Any } \\
\text { disability }\end{array}$ & Blind & $\begin{array}{l}\text { Tongue-tied } \\
\text { and/or deaf }\end{array}$ & Mental & Impaired & Others & $\begin{array}{c}\text { Not } \\
\text { disabled }\end{array}$ \\
\hline Female & 45.71 & 51.94 & 42.17 & 35.43 & 43.45 & 52.94 & 46.29 \\
\hline Male & 54.29 & 48.05 & 57.83 & 64.57 & 56.55 & 47.06 & 53.71 \\
\hline Rural & 47.42 & 40.52 & 56.02 & 49.61 & 51.48 & 35.29 & 42.59 \\
\hline Urban & 52.58 & 59.48 & 43.98 & 50.39 & 48.51 & 64.71 & 57.41 \\
\hline \multicolumn{8}{|l|}{ Group age } \\
\hline $15-24$ years & 19.78 & 10.03 & 34.21 & 30.00 & 17.16 & 32.26 & 27.82 \\
\hline $25-34$ years & 25.68 & 15.86 & 27.63 & 32.50 & 31.69 & 29.03 & 32.34 \\
\hline $35-49$ years & 32.68 & 40.13 & 26.32 & 28.33 & 31.35 & 19.36 & 29.37 \\
\hline 50-64 years & 21.86 & 33.98 & 11.84 & 09.17 & 19.80 & 19.35 & 10.47 \\
\hline \multicolumn{8}{|c|}{ Highest diploma } \\
\hline None & 35.34 & 25.55 & 48.18 & 54.06 & 33.62 & 45.83 & 28.43 \\
\hline FLSC & 42.50 & 45.93 & 39.09 & 28.38 & 43.83 & 50.00 & 48.49 \\
\hline GCEOL & 11.78 & 16.30 & 08.18 & 09.46 & 09.79 & 04.17 & 12.97 \\
\hline GCEAL & 05.61 & 07.41 & 02.73 & 01.35 & 06.81 & --- & 06.22 \\
\hline Bachelor & 02.81 & 01.85 & 01.82 & 02.70 & 04.68 & $\begin{array}{ll}-- \\
--\end{array}$ & 02.44 \\
\hline Master-PhD & 01.96 & 02.96 & --- & 04.05 & 01.27 & --- & 01.45 \\
\hline \multicolumn{8}{|c|}{ Cross tabulation of disability and employment in urban Cameroon } \\
\hline \multicolumn{8}{|c|}{ Men } \\
\hline Employed & 90.13 & 92.55 & 85.72 & 69.23 & 92.00 & -- & 94.18 \\
\hline Unemployed & 09.87 & 07.45 & 14.28 & 30.77 & 08.00 & -- & 05.82 \\
\hline \multicolumn{8}{|l|}{ Women } \\
\hline Employed & 86.26 & 87.88 & 64.29 & 100 & 95.00 & 88.89 & 85.49 \\
\hline Unemployed & 13.74 & 12.12 & 35.70 & --- & 05.00 & 11.11 & 14.51 \\
\hline \multicolumn{8}{|l|}{ Total } \\
\hline Employed & 88.39 & 90.16 & 16.19 & 78.95 & 93.04 & 93.33 & 90.04 \\
\hline Unemployed & 11.61 & 09.84 & 23.81 & 21.05 & 06.96 & 06.67 & 09.96 \\
\hline \multicolumn{8}{|c|}{ Cross tabulation of disability and labour market sectors in urban Cameroon } \\
\hline \multicolumn{8}{|l|}{ Men } \\
\hline Public & 12.11 & 10.64 & 11.43 & --- & 17.33 & -- & 12.47 \\
\hline Private & 13.00 & 18.08 & 02.86 & --- & 12.00 & 33.33 & 13.55 \\
\hline Informal & 65.02 & 63.83 & 71.43 & 69.23 & 62.67 & 66.67 & 68.16 \\
\hline Unemployed & 09.87 & 07.45 & 14.28 & 30.77 & 08.00 & --- & 05.82 \\
\hline \multicolumn{8}{|l|}{ Women } \\
\hline Public & 09.89 & 16.16 & --- & --- & 05.00 & --- & 06.09 \\
\hline Private & 04.39 & 06.06 & 03.57 & --- & 02.50 & --- & 05.01 \\
\hline Informal & 71.98 & 65.66 & 60.72 & 100.00 & 87.50 & 88.89 & 74.39 \\
\hline Unemployed & 13.74 & 12.12 & 35.71 & --- & 05.00 & 11.11 & 14.51 \\
\hline \multicolumn{8}{|l|}{ Total } \\
\hline Public & 11.11 & 13.47 & 06.35 & --- & 13.04 & --- & 09.43 \\
\hline Private & 09.13 & 11.92 & 03.17 & --- & 08.70 & 13.33 & 09.49 \\
\hline Informal & 68.15 & 64.77 & 66.67 & 78.95 & 71.30 & 80.00 & 71.12 \\
\hline Unemployed & 11.61 & 09.84 & 23.81 & 21.05 & 06.96 & 06.67 & 09.96 \\
\hline
\end{tabular}

A significant majority of disabled are people who have either eyesight problems $(1.70 \%)$ or are impaired $(1.49 \%)$. Men are slightly over-represented among disabled people compared to 
women, with 54.3 per cent of disabled people of working age being male and 45.71 per cent being women. Interestingly, while men are over-represented among people who have diction and/or deafness problems $(57.83 \%)$, mental problems $(64.57 \%)$ and among those with a physical impairment (56.55\%), women are relatively over-represented among those with eyesight problems (51.94\%) and those with other unclassified handicaps. With 58.36 per cent of disabled people aged between 25 and 49 years, it appears from table 1 that the age distribution of disabled people is concentrated in middle classes of the working age. When it comes to their qualification, table 1 also reveals that there is a very marked difference between disabled people and non-disabled people. Among the disabled people of working age, some 35 per cent have no qualifications, compared with 28 per cent among the non-disabled working age population.

To determine how these disability measures help explain labour force participation decisions, the table 1 provides a cross tabulation of disability and employment status. Globally, disabled present greater unemployment rates than non-disabled people, meaning that they are less likely to work. For example, individuals reporting a disability present an unemployment rate which is 1.6 percentage points greater than the unemployment rate of those who are non-disabled. While for men this difference is 4 percentage points in favour of non-disabled, for women the difference, though not statistically significant, is in favour of disabled people. These differences between disability measures and between men and women those no allow to clearly determine the exact influence of disability both on labour force participation and on the sector of employment. Thus instead of concentrating only on the descriptive analysis, it is important go further in our investigation by using an econometric approach that allow quantifying the effect of disability on labour force participation.

\section{Influence of disability status on labour force participation in Cameroun}

One of the most notable characteristics of labour markets in developing countries is the coexistence of the formal and informal sectors, the formal one being made of two homogeneous sectors of employment that is the public and private ones. The informal sector comprises self-employed, unpaid family workers and casual workers with reduced job security, hazardous working conditions, and dangerous work environments. Since individuals are not randomly selected into different occupations (or unemployment status) and as factors determining labour market decisions and outcomes are different from one sector to another, we model labour force participation using the multinomial logit model as follows. Assume that individual preferences are described by a well-behaved utility function, the maximum utility attainable by individual $i$ if he chooses the employment status $j$ is given by the expression $V_{i j}=S_{i j}+\varepsilon_{i j}$, where $S_{i j}=\beta_{j}^{\prime} X_{i}$ represent the non-stochastic component, $\varepsilon_{i j}$ the stochastic component, and $X$ the vector of explanatory variables. The probability for individual $i$ to be employed in the labour market $j$ given by equation 1 :

$$
P_{i j}=\operatorname{prob}\left[S_{i j}-S_{i k}>\varepsilon_{i k}-\varepsilon_{i j}, k \neq j\right]=\frac{\exp \left(\beta_{j}^{\prime} X_{i}\right)}{\sum_{k=0}^{3} \exp \left(\beta_{k}^{\prime} X_{i}\right)}
$$

Factors influencing an individual's position in one of these segments of the labour market are determined through the estimation of equation 1 by maximum likelihood method, separately for men and women. Building on past studies and on intuitions derived from table 1, a number of explanatory variables are expected to influence this employment status. First of all, a self-reported indicator is used to measure the effect of disability on labour force participation and this variable is defined as follows in equation 2. While using such an indicator in an 


\section{Macrothink Institute}

empirical analysis of the impact of disability on labour force participation, the researcher is faced with a variety of analytical challenges amongst which is the possibility of a "justification bias" in case people with lower preferences for work justify themselves by reporting disability or when the propensity to declare any disability depends on the possibility of claiming disability benefits. Since there is no disability benefits in the Cameroon context, such a justification bias is not likely to exist and as a consequence, we believe the disability variables are exogenous.

$$
D_{i}=\left\{\begin{array}{l}
1 \text { if reported any disability } \\
\text { otherwise }
\end{array}\right.
$$

A set of other control variables are thought to influence an individual's probability of getting a job in the labour market. Foremost is an individual's level of education which, from the human capital perspective is assumed to impart knowledge and skills which are valued in the marketplace. On the other hand, according to screening and signalling theories, education is assumed to be used to separate individuals from each other since productivity differences among workers can be identified through actions that are correlated with the schooling outcome (Arrow, 1973 ; Spence, 1973). For both perspectives, high skilled individuals are more likely to be employed than low skilled individuals. In the same vein, building on the fact that the main purpose of professional training programs is the integration of unemployed individuals and persons threatened by unemployment into employment by supporting them with a set of different courses and activities, they have been cornerstones of labour market policy for many decades all around the world. As a consequence, individuals who were enrolled in a professional training program are more likely to find an employment than their counterparts who didn't follow such a program. A part from human capital variables, there are family and environmental constraints that are likely to influence an individual's probability of participating in the labour market. As far as family constraints are concerned, being a household head entails some financial constraints that create incentives to look after a job. Since men and women differ in terms of incentives and career expectations, we expect the gender status to determine an individual's decision to enter, stay on or, leave the labour market. As urban and rural areas differ in terms of the structure of the labour market, we expect that individuals living in urban areas will face more constraints in getting into the labour market.

Results from estimations are presented in tables 2A, 2B, and 2C. Overall, labour force participation decision is influenced by age, gender, status in the household, investment in human capital (education and training), and geographical location. As far as the latter is concerned, it appears that individuals living in urban areas face greater constraints in finding a job and, as a consequence, are less likely to participate to the labour market. Age has a non-linear effect on the labour market participation probability and this effect depends on an individual's sex. As, compared to those who are above 49 years, individuals whose age is between 15 and 34 are less likely to be recruited in the public sector. Men whose age is between 15 and 34 are more likely to be recruited both in the formal and informal sectors of the labour market. As far as women are concerned, they have face $1.0 \%$ less chances to participate to the public sector, $5.5 \%$ less chances to be recruited in the informal sector and $2.6 \%$ more chances to be crowded in the informal sector of the Cameroon labour market. As expected, heading a household is associated with financial pressures that create incentives to participate to the labour market. It is important to point out the fact that such a pressure is more pronounced for men than for women. In fact, using the Relative Risk Ratios (RRR) ${ }^{2}$, the coefficients obtained for men are 9.281 for the public sector, 6.885 for the formal private sector and 5.295, while for women these coefficients are 3.196, 3.989 and 1.957 respectively for the 
public, the formal private and the informal sector. These differences between men and women may account for the women's position as "second income earner" in most households of Cameroon.

Investment in general and specific human capital appears to exert a positive influence on individuals' access to the labour market. For instance, investing in general education is positively associated with participation in the formal sectors of the labour market, for both genders. For the male sex and in comparison with those who didn't attend school, having studied up to the tertiary level of education induces a RRR of 6.169 between working in public sector and not working equal, while the same RRR is around 1.571 for the formal private sector, and 0.096 for the informal sector. As far as women are concerned, the same RRRs are equal to 45.92 for working in the public sector, 11.47 for working in the formal private sector, and 0.181 for working in the informal sector. These coefficients indicate that higher levels of education reduce the probability of working in the informal sector and that women's returns to education in terms of access to the labour market are higher than men's returns. Qualification or requalification through professional training programs is associated with greater probabilities of labour market access. These investments in specific human capital increases men's likelihood of being recruited in the public administration and in the formal private sector respectively by $4.6 \%$ and $2.7 \%$. As far as women are concerned, the labour market participation likelihood is increased by $3 \%$ for the public sector and $2.4 \%$ for the formal private sector. These results confirm Greenhalgh and Stewart (1987) and Booth (1991) ideas that returns from training differ according to sex.

When it comes to the key question of this paper, which was to determine the extent to which disability affects labour force participation in the Cameroon labour market, our results show that, in general the effect of disability is negative. For instance, individuals suffering from a disability face a relative risk ratio of not participating into the labour force. These RRRs are around 0.639 for not working in the public sector, 0.630 for not working in the formal private sector, and 0.632 for not working in the informal sector. These effects differ according to an individual's sex with disabled men facing greater constraints of participating in both the public and the formal private sectors of the Cameroon labour market, while these effects are not statistically significant for women ${ }^{3}$. These coefficients indicate that the disability status reduces men's probability of getting into the labour market by $0.8 \%$ for the public sector, $0.05 \%$ for the formal private sector and by $2.9 \%$ for the informal sector.

\section{Conclusion}

This paper examines the impact of the disability upon the individual labour force participation. Using data from the Cameroon 2007 household survey and applying statistical and econometric tests, it comes out with several findings that are noteworthy but the key one being the fact that disability represents a barrier to employment in the Cameroon labour market. For instance, the existence of a disability has an adverse effect on the probability of participating into the labour market, especially for men whose disability status reduces the probability of getting into the labour market by $0.8 \%$ for the public sector, $0.05 \%$ for the formal private sector and by $2.9 \%$ for the informal sector. While women and individuals living in the urban area face greater constraints in entering the labour market, other characteristics such as education, professional training, and household-head status increase the probability of getting a job in the Cameroon. 
Table 2A: Multinomial logit estimation of the impact of disability on labour market participation

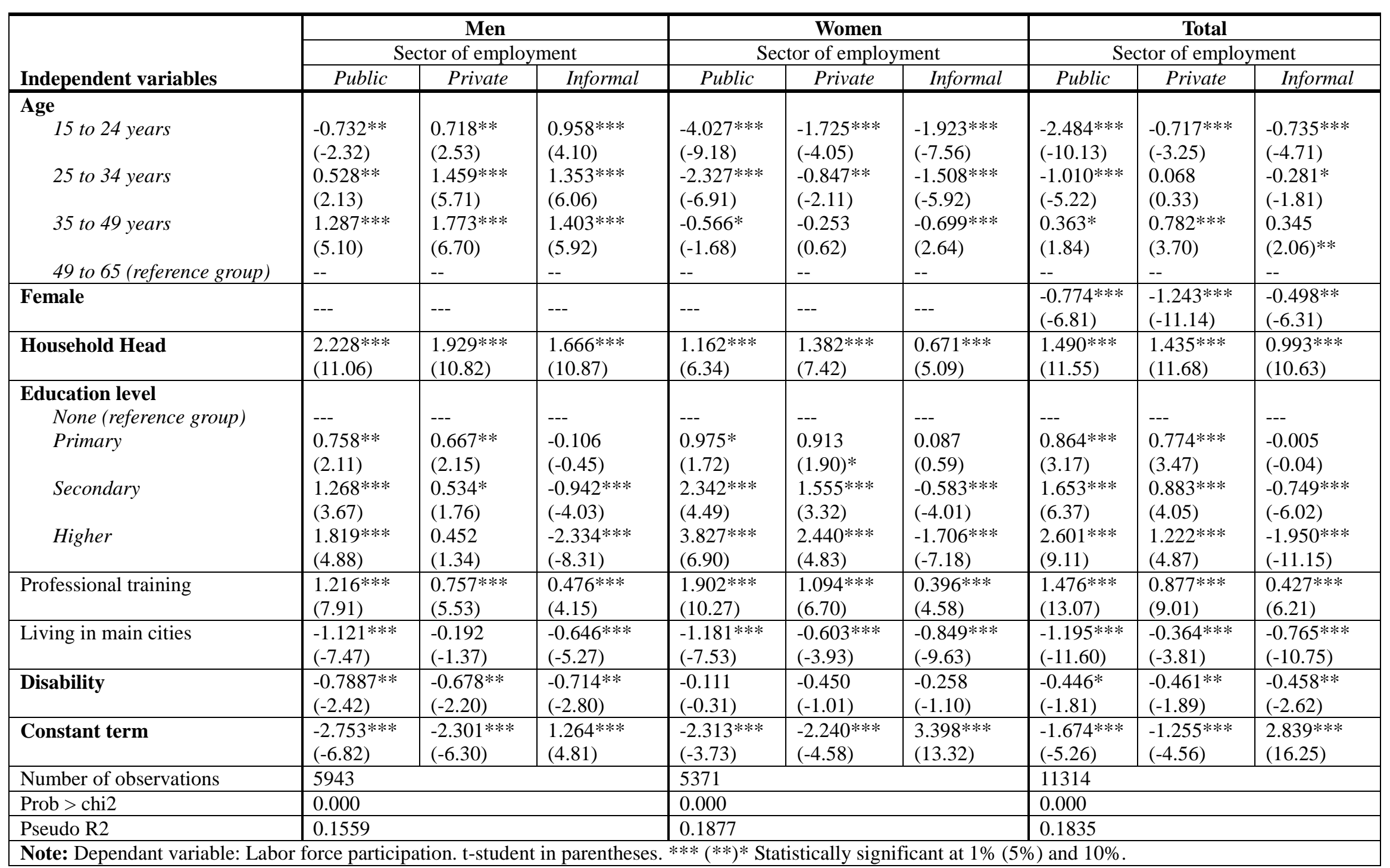


Table 2B: Marginal effect from Multinomial logit estimation of the disability impact on labour market participation

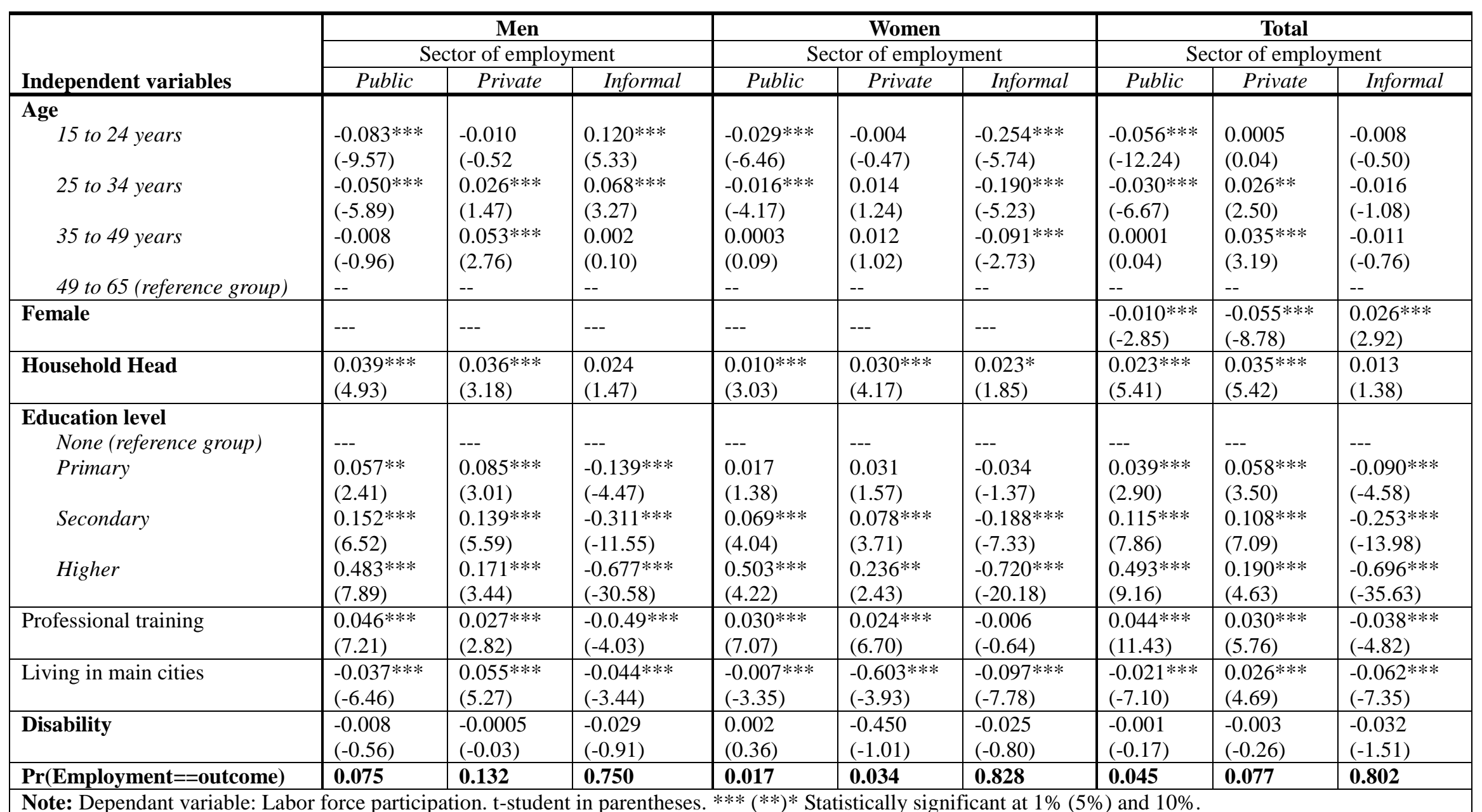


Table 2C: Multinomial logit estimation of the Relative Risk Ratios of the effect of disability on labour market participation

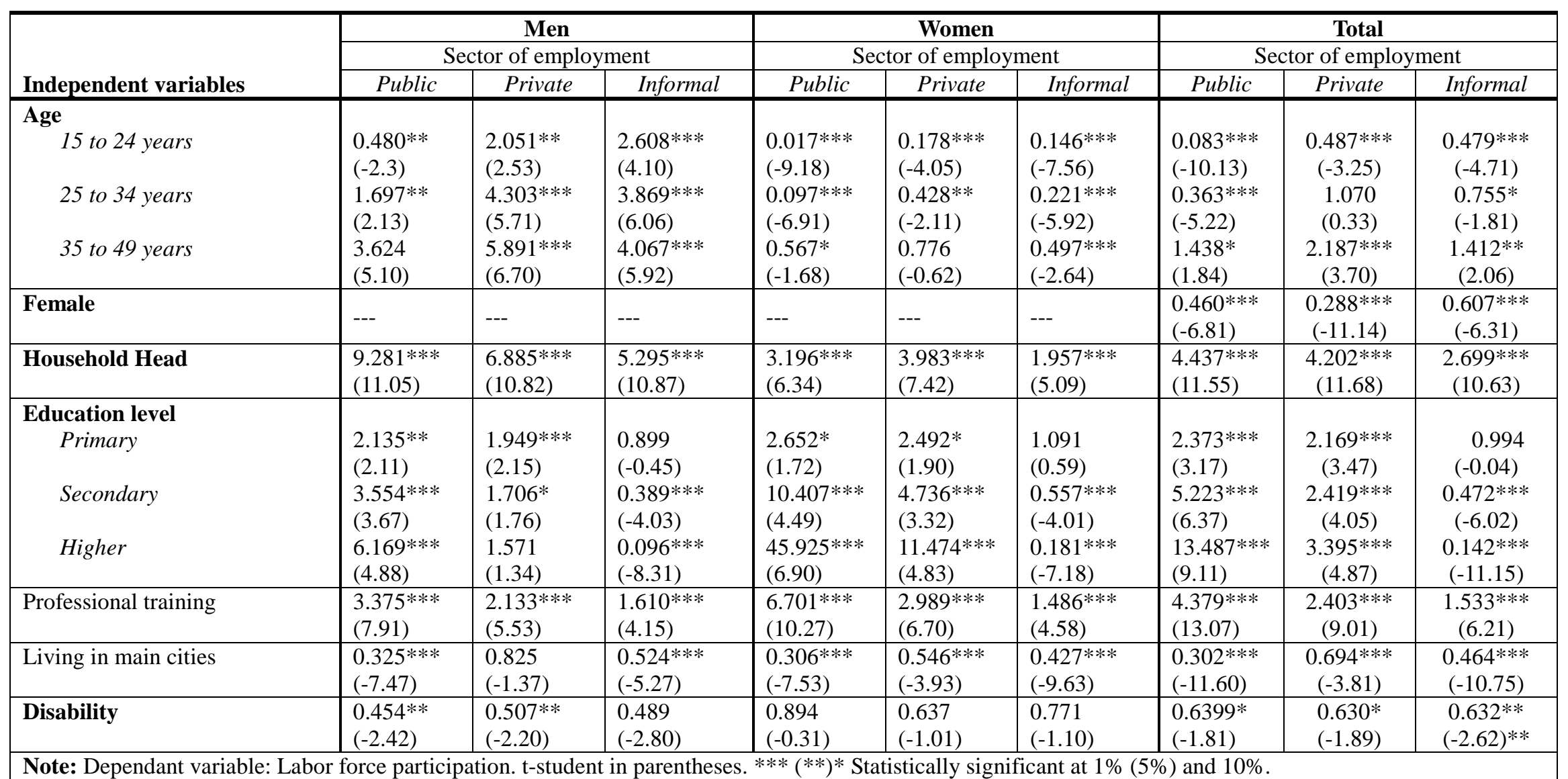




\section{References}

Baldwin, M.L. \& Johnson, W.G. (1992). Estimating the employment effects of wage discrimination. The Review of Economics and Statistics, 74(3), 446-455.

Baldwin, M.L. \& Johnson, W.G. (1994). Labor market discrimination against men with disabilities. Journal of Human Resources, 29(1), 1-19.

Baldwin, M.L. \& Johnson, W.G. (1995). Labor market discrimination against women with disabilities. Industrial Relations, 34(4), 555-577.

Barnes, C. (1991). Disabled people in Britain and discrimination: a case for anti-discrimination legislation. Hurst and $\mathrm{Co}$ in association with the British Council of Organisations of Disabled People, London. http://disability-studies. leeds.ac.uk/files/library/Barnes-disabled-people-and-discrim-ch10.pdf

Bartley, M \& Owen, C. (1996). Relation between socioeconomic status, employment, and health during economic change, 1973-93. British Medical Journal, 313, 445-449.

Becker, G. S. (1964). Human capital. New York, Columbia University Press.

Becker, G. (1971). The economics of discrimination. Chicago: University of Chicago Press.

Blackaby, D., Clark, K., Drinkwater, S., Leslie, D., Murphy, P. \& O’Leary, N. (1999). Earnings and employment opportunities of disabled people. Department for Education and Employment, Research Report No.133, Nottingham. https://www.education.gov.uk/ publications/eOrderingDownload/RB133.pdf

Blanck, P.D., Sandler, L.A., Schmeling, J.L. \& Schwartz, H.A. (2000). The emerging workforce of entrepreneurs with disabilities: preliminary study of entrepreneurship in Iowa. Iowa Law Review, 85, 1583-1668.

Booth, A.L. (1991). Job-related formal training: who receives it and what is it worth? Oxford Bulletin of Economics and Statistics, 53, 281-294.

Boylan, A. \& Burchardt, T. (2002). Barriers to self-employment for disabled people. Report for the Small Business Service, October 2002.

Daunt, P. (1992). Meeting disability: a European perspective. Cassell Education, London.

Greenhalgh, C.A. \& Stewart, M.B. (1987). The effects and determinants of training. Oxford Bulletin of Economics and Statistics, 49, 171-189.

Grossman, M. (1972). On the concept of health capital and the demand for health. Journal of Political Economy, 80, 223-255.

Hale, T., Hayghe, H. \& McNeil, J. (1998). Persons with disabilities: labor market activity, 1994. Monthly Labor Review, 3-12.

Heckman, J. (1976). The common structure of statistical models of truncation, sample selection and limited dependent variables and simple estimators for such models. Annals of Economic and Social Measurement, 5(4), 475-492.

Hotchkiss, J.L. (2004). Growing part-time employment among workers with disabilities: marginalization or opportunity? Economic Review Federal Reserve Bank of Atlanta, Third Quarter.

Jones, M.K., Latreille, P.L. \& Sloane, P.J. (2003). Disability, gender and the labour market. IZA Discussion Paper, no. 936. Institute for the Study of Labor, Bonn Germany.

Kidd, M.P., Sloane, P.J., \& Ferko, I. (2000). Disability and the labour market: an analysis of 
British males. Journal of Health Economics, 19(6), 961-981.

Madden, D. (2004). Labour market discrimination on the basis of health: an application to UK data. Applied Economics, 36, 421-442.

Martin, J., Meltzer, H. \& Elliot, D. (1988). The prevalence of disability among adults. Volume 1 de OPCS surveys of disability in Great Britain. H.M. Stationery Office, London.

Martin, J. \& White, A. (1988). The financial circumstances of disabled adults living in private households. Volume 2 de Opcs Surveys of Disability in Great Britain Series. H.M. Stationery Office, London.

Meager, N., Bates P., Dench, S., Honey, S. \& Williams, M. (1998). Employment of disabled people: assessing the extent of participation. Department for Education and Employment Research Brief No. 69, London.

Mitra, S. \& Sambamoorthi, U. (2008). Disability and the rural labor market in India: evidence for males in Tamil Nadu", World Development, 36(5), 934-952.

Oliver, M. (1985). Discrimination. disability and social policy. in Brenton, M. and Jones, C. (eds.) The yearbook of social policy, 1984/5, Routlege and Kegan Paul, London.

Oliver, M. \& Barnes, C. (1991). Discrimination, disability and welfare: from needs to rights, in Bynoe, I., Oliver, M. \& Barnes, C. Equal rights for disabled people. Institute for Public Policy Research, London.

Phelps, E.S. (1972). The statistical theory of racism and sexism. American Economic Review, 62(4), 659-661.

Schumacher, E.J. \& Baldwin, M.L. (2000). The Americans with disabilities act and the labor market experience of workers with disabilities: evidence from the SIPP. Working Paper 0013, East Carolina University, Department of Economics.

Schur, L. (2003). Barriers or opportunities? The causes of contingent and part-time work among people with disabilities. Industrial Relations, 42, 589-622.

Schur, L \& Kruse, D. (2002). Non-standard work arrangements and disability income. Report to the Disability Research Institute, University of Illinois Urbana-Champaign. http://www.dri.uiuc.edu/research/p01-03c/final technical_report_p01-03c.pdf.

Smith, A. \& Twomey, B. (2002). Labour market experience of people with disabilities. Labour Market Trends, August, 415-427.

Stronks, K., van de Mheen, H., van den Bos, J. \& Makenbach, J.P. (1997). The interrelationship between income, health and employment status. International Journal of Epidemiology, 26, 592- 599.

\section{Notes}

\footnotetext{
${ }^{1}$ The reservation wage is defined as the lowest wage at which a person is willing to work (Mitra et Sambamoorthi, 2008).

${ }^{2}$ The relative risk ratio (RRR) is a transposition of the odds ratios computed in a logistic regression to the
} 
multinomial logistic regression case. In fact, when one has $\mathrm{n}$ groups and sets group 1 to be the baseline group, the multinomial regression model would have n-1 sets of results, and RRR would be predicting the odds of being in each one of the remaining $\mathrm{n}-1$ groups as compared to group 1.

3 Disabled men's RRRs of not participating to the labour market are equal to $0.454,0.507$ and 0.489 respectively for the participation in the public, formal private and informal sectors of the Cameroon labour market. 